\title{
Hipersensibilidade alimentar em cães
}

\author{
[Food hypersensitivity in dogs] \\ P.S. Salzo ${ }^{1}$, C.E. Larsson ${ }^{2}$ \\ ${ }^{1}$ Universidade Metodista de São Paulo \\ Av. Dom Jaime Barros Câmara, 100 \\ 09895-400 - São Bernardo do Campo, SP \\ ${ }^{2}$ Faculdade de Medicina Veterinária e Zootecnia - USP - São Paulo, SP
}

\section{RESUMO}

Realizou-se um estudo retro e prospectivo em 117 cães com prontuários suspeitos de apresentarem hipersensibilidade alimentar. Os animais foram distribuídos em dois grupos: os do grupo I $(n=86)$ foram atendidos em 1993 e 1994 e os do grupo II $(n=31)$ em 1995. Os cães de ambos os grupos foram caracterizados quanto aos aspectos epidemiológicos e clínicos. Os do grupo II foram submetidos a exames complementares para a diferenciação diagnóstica do prurido, incluindo: hemograma, micológico e parasitológico cutâneo, coproparasitológico, histológico de pele e sorológicos - RAST (radioimunoensaio) e ELISA (ensaio imunoenzimático) - ambos para determinação de IgE contra antígenos alimentares -, e ao exame da dieta de eliminação seguida pela exposição provocativa. Este último exame foi o mais confiável para o estabelecimento do diagnóstico, ao determinar que 20 cães, provenientes de ambos os grupos, eram alérgicos a alimentos. Pelos RAST e ELISA, não foi possível demonstrar resultados confiáveis quando comparados aos resultados com a dieta de eliminação. Os animais acometidos foram principalmente machos, com raça definida e na faixa etária de um a seis anos. Os principais alimentos incriminados foram a carne bovina, o arroz e a carne de frango.

Palavras-chave: cão, dermatologia, alergia alimentar

\begin{abstract}
From 1993 to 1995, 117 cases of dogs suspected of food hypersensitivity were reviewed and analyzed. The animals were distributed in two groups: group I included 86 dogs assisted in the first two years of the study; and group II included 31 dogs that were observed in 1995. Dogs from both groups were characterized according to clinical and epidemiological aspects. Animals from group II were also submitted to exams in order to eliminate other similar causes of pruritus and to establish the diagnosis of food hypersensitivity, including complete blood counting, fungal culture, skin scraping, fecal exam, skin histopathology, and RAST and ELISA (both for the detection of serum IgE against food allergens), as well as test of elimination diet followed by provocative exposure. Elimination diet test proved to be the most reliable tool for definitive diagnosis of food allergy, considering 20 dogs from both groups. It was possible to conclude that male pure bred dogs from one to six-year-old were most affected and RAST and ELISA were not reliable tests for the diagnosis. The most incriminated foods were beef, rice, and chicken.
\end{abstract}

Keywords: dog, dermatology, food allergy

\section{INTRODUÇÃO}

O diagnóstico diferencial das dermatopatias de etiologia alérgica dos carnívoros domésticos constitui constante desafio ao clínico veterinário.
$\mathrm{Na}$ maioria das vezes, o diagnóstico baseia-se apenas na análise da anamnese e das lesões cutâneas elementares, evidenciadas no exame físico dos animais acometidos. Ainda são escassas as provas diagnósticas realmente efetivas e confiáveis.

Recebido em 29 de abril de 2008

Aceito em 10 de fevereiro de 2009

E-mail: paulosalzo@hotmail.com 
A hipersensibilidade alimentar, ou dermatite trofoalérgica, inclui-se entre as dermatopatias de origem alérgica e, na espécie canina, é a terceira em importância quanto à frequência, dispondo-se logo após a dermatite alérgica à picada de pulgas e à dermatite atópica ( Muller et al., 1989; Scott et al., 2001).

A hipersensibilidade alimentar é uma reação orgânica adversa aos alimentos que envolve, no seu mecanismo etiopatogênico, uma resposta alérgica. A fisiopatologia exata de a hipersensibilidade alimentar ainda não está bem estabelecida. Acredita-se que haja o envolvimento das reações de hipersensibilidade dos tipos I, III e IV e que as habituais fontes proteicas e de carboidratos encontradas na alimentação constituem os principais agentes alergênicos (Gross et al., 2005).

A resposta alérgica, frente a diferentes constituintes alimentares, pode determinar alterações nos diversos sistemas orgânicos, todavia as manifestações cutâneas são as que mais afligem os proprietários dos animais. A despeito do intenso prurido, por vezes, não se detectam lesões cutâneas. O quadro dermatológico não é muito específico, sendo, muitas vezes, confundido com o de outras dermatopatias alérgicas, parasitárias ou mesmo bacterianas (Scott et al., 2001).

Para o diagnóstico final, o clínico, habitualmente, vale-se de vários recursos, incluindo: exames parasitológico de raspado cutâneo e micológico de pelame e de escamas, histológico de pele submetida à biopsia, e testes intradérmicos e de dieta de eliminação seguida pela exposição provocativa. Tal dieta, a despeito de constituir, há muito, uma das principais ferramentas do clínico, sempre foi reputada como um procedimento trabalhoso, gerando perda de tempo do proprietário, não só na busca dos seus constituintes, como, também, no preparo da alimentação. Nos últimos anos, temse observado a introdução no mercado de dietas comerciais com restrição das fontes proteica e de carboidratos. Por vezes, são constituídas de ingredientes proteicos hidrolisados, constituindo nova opção para o diagnóstico e mesmo para a manutenção dos animais comprovadamente alérgicos.
Com o advento de provas sorológicas para a detecção de $\operatorname{IgE}$ alimento-específica, iniciou-se uma verdadeira revolução nos procedimentos diagnósticos. Todavia, muito pouco se conhece sobre suas sensibilidade e especificidade (Jackson, 2004). A relação custo-benefício, por se tratar de provas onerosas, é sempre discutida entre os clínicos e entre estes e os proprietários instados a custeá-las.

Os objetivos deste trabalho foram estudar a ocorrência da hipersensibilidade alimentar, a caracterização epidemiológica do animal acometido, o quadro clínico dela decorrente e a resposta do animal frente ao uso dos glicocorticoides.

\section{MATERIAL E MÉTODOS}

Entre janeiro de 1993 e dezembro de 1995, foram atendidos, no Serviço de Dermatologia do Departamento de Clínica Médica e do Hospital Veterinário da Faculdade de Medicina Veterinária e Zootecnia da Universidade de São Paulo, 117 cães com diagnóstico presuntivo de hipersensibilidade alimentar. Destes, 86 foram identificados por levantamento retrospectivo (janeiro/1993-dezembro/1994), mediante a análise de prontuários arquivados (grupo I). Os outros 31 animais, atendidos entre janeiro e dezembro de 1995, foram acompanhados prospectivamente e submetidos a exames complementares incluídos no protocolo experimental. Foram também submetidos a exames complementares, como o histológico de pele e os sorológicos de imunodiagnóstico (grupo II).

Todos os cães, após prévia identificação, foram submetidos à anamnese detalhada, a exames físico geral, dermatológico e otológico. Tais procedimentos foram complementados, em parte, com uma série de exames, a saber: micológico (lâmpada de Wood e cultivo micológico), parasitológicos de raspado cutâneo e de cerume, hematimetria e coproparasitológico.

Foram incluídos apenas animais com quadro compatível com o diagnóstico presuntivo de hipersensibilidade alimentar, afastando-se todos aqueles com evidências clínicas de acometimento por outras dermatopatias: alérgicas (atopia, dermatite alérgica por picada de pulgas e/ou ixodídeos, dermatite de contato 
alérgica), parasitárias (escabiose, demodiciose, puliciose, pediculose, ixodidiose), piogênicas (foliculite bacteriana superficial, síndrome foliculite-furunculose-celulite), hormonais , seborreicas, dentre outras.

A realização da anamnese e dos exames físico geral, dermatológico e otológico e a dieta de eliminação com exposição provocativa foram similares para os animais de ambos os grupos, porém somente os animais do grupo II foram submetidos a protocolo de exames complementares que incluíram o hemograma e a colheita de sangue e do soro. $O$ soro foi armazenado à temperatura de congelamento, para posterior realização dos exames sorológicos RAST $^{1}$ e ELISA ${ }^{2}$. Esses exames sorológicos visaram à detecção de imunoglobulinas da classe $\mathrm{E}$ (IgE) frente a painéis de antígenos alimentares. Consideraram-se positivos os resultados assinalados como altamente positivos e positivos e como negativos os negativos e borderline, segundo os valores obtidos e interpretados pelos laboratórios executores do RAST e ELISA.

Os animais do grupo II foram, ainda, submetidos, após prévia sedação ${ }^{3}$, à biópsia de pele das lesões localizadas na região cervical dorsal. Os fragmentos foram conservados em formol a $10 \%$ e submetidos às técnicas usuais de histologia.

Após a colheita das amostras, para realização dos exames complementares, propôs-se aos proprietários dos cães do grupo II a exposição à dieta de eliminação por um período padronizado de seis semanas. A dieta, constituída basicamente por alimentos com os quais o animal tinha tido pouco ou nenhum contato, até então, incluiu: uma fonte proteica (carne de carneiro, coelho ou peixe de carne branca), uma fonte de carboidratos (arroz integral e/ou batatas), óleo de milho e água mineral para cocção dos alimentos e dessedentação. Ao término de seis semanas, foram realizados, quando do retorno, a avaliação clínica e a análise dos resultados obtidos nos exames complementares. Estabeleceu-se o diagnóstico provável de hipersensibilidade alimentar quando havia melhora de $80 \%$ ou mais, em termos de redução do prurido e do número e

\footnotetext{
${ }^{1}$ Spectrum Labs, Arizona, EUA.

${ }^{2}$ Bio Medical Services, Texas, EUA.

${ }^{3}$ Acepran 0,1\%- Lab. Biochimico e Xylocaína 2\% - Merrel Lepetit - São Paulo, Brasil.
}

da intensidade das lesões, após a submissão à dieta. Esse percentual foi determinado em função da média aritmética calculada a partir dos percentuais de melhora estimados subjetivamente pelo proprietário e objetivamente pelo clínico.

Visando estabelecer o diagnóstico definitivo de hipersensibilidade alimentar, preconizou-se a execução da exposição provocativa nos cães em que se obteve a melhora de, pelo menos, $80 \%$. Após a exposição à dieta de eliminação, os animais foram reexpostos, consecutivamente, a cada sete dias, aos alimentos consumidos anteriormente. Durante a reexposição, observava-se uma possível exacerbação do quadro clínico frente a um determinado alimento. Este foi incriminado como agente causal quando ocorreu a hipersensibilidade alimentar.

Durante os sete primeiros dias de adoção da dieta de eliminação, todos os animais do grupo II e parte dos animais do grupo I foram submetidos à terapia com doses anti-inflamatórias $(0,5$ a $1,0 \mathrm{mg} / \mathrm{kg}$ ) de prednisona ${ }^{4}$ com o intuito de minimizar o quadro sintomático e avaliar a resposta dos cães com hipersensibilidade alimentar a este medicamento. Na ocasião do retorno, os proprietários foram instados a relatar a diferença de resultados quanto à diminuição do prurido, entre o período da dieta associado com a corticoideterapia e o restante das seis semanas sem medicamento.

O grau de associação entre a resposta à dieta de eliminação e os resultados dos testes sorológicos RAST e ELISA foi determinado pelo teste Fisher (Siegel, 1975; $\mathrm{P}<0,05$ ). Calcularam-se, ainda, os índices relativos de sensibilidade, especificidade, valores preditivos (positivo e negativo) e concordância entre o RAST e a dieta e o ELISA e a dieta de eliminação.

\section{RESULTADOS}

Em função da metodologia empregada, estabeleceu-se o diagnóstico de hipersensibilidade alimentar em 20 animais (15 do grupo I e 5 do grupo II), sendo 12 (60\%) machos e oito (40\%) fêmeas, $14(70 \%)$ de raça definida e seis $(30 \%)$ sem raça definida. Pela anamnese, constatou-se que o decurso evolutivo do quadro de hipersensibilidade alimentar foi

${ }^{4}$ Meticorten, Schering-Plough - São Paulo, Brasil. 
bem estabelecido em 13 (65\%) dos animais, sendo nove do grupo I e quatro do grupo II.

Dentre os 14 cães de raça definida, três $(21,5 \%)$ eram Poodle; três $(21,5 \%)$, Pinscher miniatura; dois $(14,4 \%)$, Pastor Alemão; e um de cada uma das seguintes raças: Terrier Brasileiro, Dachshund, Pequinês, Doberman, Beagle e Boxer. Relativamente à faixa etária, 15 animais $(75 \%)$ estavam, no máximo, com 72 meses de vida. Em ordem decrescente de frequência, as faixas etárias mais acometidas foram as de 48 a 72 meses (35\%), 12 a 36 meses (30\%), 84 a 108 meses $(15 \%)$ e de até 11 meses ou acima de 120 meses, ambas com $10 \%$ dos casos.

O decurso evolutivo do quadro de hipersensibilidade alimentar nos 13 casos em que essa variável pôde ser determinada era de, pelo menos, 12 meses em oito casos $(61,5 \%)$, e de 24,36 e 108 meses em dois, dois e um cães $(38,5 \%)$, respectivamente.

Em termos de magnitude de ocorrência, verificouse que o prurido foi a manifestação sintomática preponderante nos 20 casos: em $11(55,0 \%)$ cães, este ocorreu de forma localizada e, nos outros nove $(45,0 \%)$, era generalizado. Quando localizado, as regiões mais acometidas eram a lombar e a de membros (torácicos e pélvicos), vindo a seguir as regiões abdominal, facial, axilar e da genitália. Doze cães, sete do grupo I, e cinco do grupo II, apresentavam quadro otopático concomitante, qual seja, de otite externa eczematosa bilateral $(60 \%)$.

Não foram observados sintomas referentes ao trato gastrentérico ou relativos a outros sistemas.

Em três cães, as lesões foram generalizadas e nos demais, localizadas, sendo sete na região lombar, seis em abdômen ventral, cinco na região torácica, cinco nos membros torácicos ou pélvicos e dois na cervical, axilar, facial, tóraco-abdominal. Foram evidenciadas também lesões com localização perineal, cervical e lombar, facial e torácica, lombar e abdominal ventral, lombar e de membros e lombar e axilar. Quanto ao tipo de lesão, observaram-se: eritema em 11 (55\%) casos, alopecia em $10(50 \%)$, crostas em nove (45\%), escamas micáceas ou furfuráceas em sete $(35 \%)$, pápulas em três $(15 \%)$ e eritema e alopecia em três $(15 \%)$.

Dos 31 cães submetidos ao RAST, 30 (96,7\%) apresentaram anticorpos antígeno específicos. O cão remanescente $(3,3 \%)$ foi sorologicamente negativo aos alimentos testados. Entre os 30 cães submetidos ao ELISA, 18 (60\%) mostraram-se positivos e $12(40 \%)$ foram sorologicamente negativos.

Observou-se positividade em ambos os testes em 17 casos (56,7\%). Destes 17, houve concordância entre os antígenos evidenciados pelo RAST e ELISA em seis casos $(35,3 \%)$, havendo, no mínimo, um alérgeno e, no máximo, quatro alérgenos concordantes. Nestes seis casos, houve concordância entre ambas as provas frente a um mesmo alérgeno no soro de quatro animais, a dois alérgenos em um e a quatro alérgenos, também em um caso. Positividade ao RAST e negatividade ao ELISA foram verificadas em 12 casos (40\%), e negatividade ao RAST e positividade ao ELISA em um caso $(3,3 \%)$.

Na Tab. 1 apresentam-se os resultados de RAST e ELISA e o teste de dieta de eliminação, realizados, respectivamente, em 31 soros, 30 soros e 31 animais do grupo II. Em função das frequências absolutas, calcularam-se os valores relativos de sensibilidade, especificidade, valores preditivos positivo e negativo (VPR+ e VPR-) e concordância para cada um dos testes de "per se" (Tab. 2). Verificou-se não haver associação entre as provas diagnósticas estudadas $(\mathrm{P}>0,05)$.

Dos 117 cães submetidos à dieta de eliminação $(86$ do grupo I e 31 do grupo II), 44 (37,6\%) apresentaram melhora de, pelo menos, $80 \%$ relativamente ao quadro clínico, sendo 38 (44,2\%) do grupo I e seis $(19,3 \%)$ do grupo II. O tempo necessário para se obter uma resposta à dieta pôde ser bem estabelecido apenas nos seis animais do grupo II. Em cinco deles $(83,4 \%)$, evidenciou-se nítida melhora após seis semanas da adoção da dieta e em um animal $(16,6 \%)$ a melhoria foi observada já após três semanas.

Tabela 1. Resultados obtidos com RAST e ELISA e o teste da dieta de eliminação em cães atendidos em 1995 no Hospital Veterinário da Faculdade de Veterináriae Zootecnia da Universidade de São Paulo

\begin{tabular}{lcccccc}
\multicolumn{1}{c}{ Dieta } & Rast + & Rast- & Total & Elisa+ & Elisa- & Total \\
\hline Responsivo & 5 & 0 & 5 & 3 & 2 & 5 \\
Não responsivo & 25 & 1 & 26 & 15 & 10 & 25 \\
Total & 30 & 1 & 31 & 18 & 12 & 30 \\
\hline
\end{tabular}


Tabela 2. Valores de sensibilidade, especificidade, preditivos (positivos e negativos) e de concordância para RAST e ELISA e o teste de dieta de eliminação em cães atendidos em 1995 no Hospital Veterinário da Faculdade de Medicina Veterinária e Zootecnia da Universidade de São Paulo

\begin{tabular}{lcc}
\hline & RAST & ELISA \\
\hline Sensibilidade & 100,0 & 60,0 \\
Especificidade & 3,85 & 40,0 \\
VPR+ & 16,7 & 16,7 \\
VPR- & 100,0 & 83,3 \\
Concordância & 19,3 & 43,3 \\
\hline VPR'
\end{tabular}

VPR: valor preditivo.

Entre os 44 animais que apresentaram melhora frente à dieta hipoalergênica, $36(81,8 \%)$ foram submetidos à exposição provocativa. Em 20 $(55,5 \%)$ deles, foi possível a identificação do(s) alimento(s) causador(es) da dermatopatia, 15 nos do grupo I e cinco nos do grupo II. As frequências dos alimentos identificados após a exposição provocativa são apresentadas na Tab. 3.

Tabela 3. Alimentos envolvidos no desencadeamento de reação de hipersensibilidade alimentar em 20 cães atendidos em 1995 no Hospital Veterinário da Faculdade de Medicina Veterinária e Zootecnia da Universidade de São Paulo

\begin{tabular}{lcc}
\multicolumn{1}{c}{ Composição } & $\mathrm{N}$ & $\%$ \\
\hline Carne bovina & 7 & 35 \\
Arroz & 4 & 20 \\
Carne de frango & 3 & 15 \\
Carne de frango e bovina & 3 & 15 \\
Carne especial para cães & 1 & 5 \\
Arroz e carne de frango & 1 & 5 \\
Vários* & 1 & 5 \\
\hline *Ração comercial, pão, produtos lácteos e carne \\
bovina
\end{tabular}

Concomitantemente à introdução da dieta hipoalergênica, prescreveu-se, para 11 animais (seis do grupo I e cinco do grupo II) acometidos por hipersensibilidade alimentar, terapia adjuvante, durante os sete dias iniciais da dieta, com prednisona per os $(0,5-1,0 \mathrm{mg} / \mathrm{kg} / \mathrm{dia})$. Dez $(90 \%)$ animais apresentaram franca melhora em termos de remissão do intenso prurido bem como das lesões. Essa melhora perdurou durante todo o período de manutenção da dieta, mesmo com a descontinuação da prednisona.
Não foram evidenciadas alterações significativas que pudessem alterar o diagnóstico dos animais nos seguintes exames: hemograma, histológico de biópsias cutâneas, micológico de pelame, parasitológico de raspado cutâneo e coproparasitológico.

\section{DISCUSSÃO}

Os resultados sugerem predominância de hipersensibilidade alimentar em machos e em animais de raça definida. As raças mais frequentemente envolvidas, Poodle e Pinscher, o foram, provavelmente, em razão do maior número de atendimento dessas raças. De acordo com White (1994), a hipersensibilidade alimentar deve sempre constar do diagnóstico diferencial de prurido em cães jovens com menos de um ano de idade. Neste estudo, encontrou-se predomínio de animais entre quatro e seis anos de idade. Segundo a literatura, há consenso entre os autores sobre a inexistência de predisposição sexual (Jeffers et al., 1991; Roudebush, 2004). Segundo Rosser (1993) e Kwochka (2000), as raças Dálmata, West Highland White Terrier, Collie, Shar Pei, Cocker Spaniel, Springer, Schnauzer, Lhasa Apso e Labrador seriam as de maior risco de acometimento.

Em sete (35\%) dos 20 animais acometidos por hipersensibilidade alimentar, não foi possível determinar a evolução do quadro clínico, pois esta era desconhecida pelos proprietários. Nos demais $13(65 \%)$ cães, a presença dos sintomas de reação adversa variavam entre um e três anos de contato com o(s) alimento(s), similar ao disposto na literatura (Jeffers et al., 1991; Rhodes, 1995; Kwochka, 2000).

O prurido, mormente o localizado, foi o sintoma predominante, entre as manifestações pruriginosas. Rosser (1993), em estudo realizado com 51 cães, observou resultados semelhantes, enquanto White (2000) notou predominância de quadro generalizado. A maioria dos autores consultados afirma ser o prurido o sintoma mais importante dentre os constatados nas reações adversas aos alimentos (Baker 1990; Rosser 1993; Fadok 1994), e não parece haver uma distribuição padrão e bem caracterizada, sendo a hipersensibilidade alimentar frequentemente indistinguível, clinicamente, de dermatopatias, tais como a dermatite atópica, a dermatite 
alérgica à picada de pulgas e a escabiose (Rhodes, 1995; Kwochka, 2000; Martin, 2004).

Nenhum cão dentre os acometidos por hipersensibilidade alimentar apresentou quaisquer sintomas de gastrenterite ou mesmo sintomatologia em outros sistemas passíveis de serem relacionados com a ingestão de alimentos. Este dado está em concordância com os dispostos na literatura, referentes à baixa ocorrência de manifestações em outros sistemas além do ototegumentar (Jeffers et al., 1991; Roudebush e Cowelt, 1992; Scott et al., 2001).

Em nenhum dos 20 cães foi possível determinar se o quadro de hipersensibilidade alimentar era sazonal ou perene, provavelmente devido à falta de observação cuidadosa por parte dos proprietários. $\mathrm{Na}$ literatura há consenso de que o prurido na hipersensibilidade alimentar é tipicamente perene (Jeffers et al., 1991; Rosser, 1993; Jackson, 2004).

Dentre as principais lesões cutâneas observadas, destacam-se eritema, alopecia e crostas, assestadas principalmente em região lombar e abdômen. Em nenhum dos cães foram identificadas lesões características de piodermite superficial ou profunda, ou urticária secundária ao quadro de base. Lesões eritematosas e papulares são descritas, pela maioria dos autores, como sendo muito frequentes na hipersensibilidade alimentar. A presença de foliculites bacterianas recidivantes, dermatite piotraumática e de quadros urticariformes é considerada, também, como resultante de uma enfermidade de base que poderia ser a hipersensibilidade alimentar (Baker, 1990; Kwochka, 2000; Kennis, 2006). A otite eczematosa, modalidade frequente de otopatia de fundo alérgico, foi a entidade mórbida mais comumente evidenciada em associação com a hipersensibilidade alimentar. Este resultado confirma o já disposto na literatura, em que a otite externa é frequentemente observada nos casos de hipersensibilidade alimentar, acompanhando os demais aspectos clínicos, e que, em algumas ocasiões, pode estar presente como a única manifestação clínica (Kwochka, 2000; Kennis, 2006).

A observação e a comparação dos casos clínicos arrolados com a casuística disposta na literatura (Scott et al., 2001; Gross et al., 2005) mostram que não existe nenhum padrão clássico de lesões cutâneas que sejam patognomônicas da hipersensibilidade alimentar em cães.

Dentre os testes sorológicos utilizados, o RAST apresentou alta sensibilidade, mas com especificidade muito baixa, pois detectou um grande número de falsos positivos quando comparado à dieta de eliminação. Pelo emprego do teste Fisher, notou-se que o RAST não se associou $(\mathrm{P}>0,05)$ à dieta de eliminação, ou seja, ele não foi um bom teste para detecção de animais realmente alérgicos a alimentos. Do mesmo modo, pela determinação dos valores preditivos, observou-se que pelo RAST um resultado positivo poucas vezes o foi realmente, enquanto o resultado negativo provavelmente estampou a verdadeira negatividade.

Quanto ao ELISA, verificou-se sensibilidade menor que aquela observada com o emprego do RAST, todavia com especificidade bem maior, já que o número de falsos positivos foi de menor magnitude. Contudo, pelos valores preditivos, notou-se que, para o ELISA, tanto os resultados positivos como negativos nem sempre são realmente verdadeiros. Pelo teste Fisher notouse, também, ausência de associação entre o teste ELISA e a dieta de eliminação, devendo, portanto, ser preconizado como um teste fidedigno para o diagnóstico de alergia alimentar.

A associação entre RAST e ELISA foi pequena. Resultados similares foram observados por MacDonald (1993) e Scott et al. (2001). Apesar de a patogenia da hipersensibilidade alimentar em cães ainda não ser totalmente conhecida, sabe-se que nem toda reação adversa a alimentos é imune mediada e, ainda, que as reações que são mediadas imunologicamente nem sempre envolvem a fração $\mathrm{IgE}$, podendo englobar as reações de hipersensibilidade dos tipos II, III ou IV. Há, ainda, um outro problema que deve ser considerado quando da comparação de resultados com os ora obtidos. Ele diz respeito ao fato de estes testes não levarem em conta os efeitos da cocção, do processamento, da digestão e da metabolização, entre outros, sobre o alimento consumido in natura. Apesar das aparentes vantagens de rapidez, facilidade de realização e da não necessidade de exposição provocativa, a confiabilidade desses testes não será patente até 
que se conheça melhor a patogenia da hipersensibilidade alimentar (Kennis, 2006).

A interpretação dos resultados dos exames histológicos de lesões cutâneas não permitiu demonstrar qualquer alteração que pudesse ser considerada patognomônica ou característica da hipersensibilidade alimentar. Os achados histológicos nos animais do grupo II, tanto nos alérgicos como nos não alérgicos a alimentos, podem ser considerados similares entre si e aos de quaisquer outras dermatopatias alérgicas, indicando, portanto, que o histológico do tegumento não é um exame complementar útil para o estabelecimento do diagnóstico de hipersensibilidade alimentar. Esta assertiva encontra embasamento em trabalhos publicados por White (1994), Scott et al. (2001) e Gross et al. (2005).

A dieta de eliminação, manipulada no domicílio do proprietário e composta por alimentos ainda não usados, mostrou-se ser a forma mais confiável de detecção dos animais alérgicos a alimentos. A privação dos animais de sua dieta original, por um período de tempo predeterminado, juntamente com a posterior exposição provocativa, possibilitou o estabelecimento do diagnóstico em 20 cães. O uso da dieta de eliminação como forma de diagnóstico da hipersensibilidade alimentar em cães é a forma mais antiga e até hoje a única considerada padrão, sendo aceita mundialmente por dermatologistas veterinários e alergologistas humanos (Jeffers et al., 1991; MacDonald 1993; Kwochka, 2000).

No presente trabalho, o período padrão de duração da dieta de eliminação foi o de seis semanas. Alguns autores divergem quanto a essa duração. Baker (1990), Jeffers et al. (1991) e Rhodes (1995) preconizaram que três semanas seria suficiente, e MacDonald (1993) que fosse acima de 28 dias, podendo perdurar até por 12 semanas. Um dos trabalhos que mais contribuiu para elucidar esse aspecto foi o de Rosser (1993). Esse autor estudou 51 cães e observou que, se a dieta perdurasse por apenas três semanas, como preconizado até então pela maioria dos autores, em 38 animais $(74,5 \%)$ não se poderia ter estabelecido o diagnóstico de alergia alimentar. Fadok (1994) criticou as dietas de eliminação caseiras mantidas por tempo prolongado, pois dietas de eliminação de 21 e 28 dias não só permitiriam evidenciar nítida melhora, mas também poderiam evitar um indesejável e severo desequilíbrio nutricional.

Neste trabalho, após seis semanas, observou-se nítida melhora do quadro dermatológico em 44 cães. A fim de que se obtivesse plena confirmação do diagnóstico de hipersensibilidade alimentar, 36 animais foram reexpostos ao arraçoamento prévio, para uma possível observação de exacerbação dos sintomas cutâneos. Em 20 deles, ressurgiram os sintomas clínicos, obtendo-se, então, o diagnóstico definitivo de hipersensibilidade alimentar, bem como a evidenciação dos ítens alimentares desencadeadores do quadro. Nos outros 16 cães, não foi possível a confirmação do diagnóstico aventado, por não terem eles manifestado exacerbação da sintomatologia após a exposição. Pode-se creditar o insucesso ao período curto, sete dias de reexposição de cada um dos alimentos suspeitos, apesar de ser este o período indicado por muitos pesquisadores. Fadok (1994) afirmou que a maioria dos cães com hipersensibilidade alimentar desenvolve exacerbação sintomática cerca de 72 horas após a reintrodução da dieta anterior. Rosser (1993) identificou quatro casos de exacerbação após o período de sete dias inicialmente proposto.

Cerca de $20 \%$ dos cães não foram submetidos a esta etapa do protocolo, portanto não tiveram o diagnóstico clínico totalmente confirmado, já que seus proprietários não adotaram tal procedimento.

Apenas Jeffers et al. (1991) e White (2000) indicaram os alimentos desencadeadores do quadro, como foi feito neste estudo. A carne bovina foi considerada como um dos alimentos mais incriminadores, seguida do leite e derivados e, finalmente, os cereais (Martín et al., 2004; Roudebush, 2004).

A dieta de eliminação caseira é considerada ideal para o estabelecimento do diagnóstico de hipersensibilidade alimentar, pois contém uma fonte controlada de proteína e de carboidrato além de ser livre de aditivos, conservantes e corantes. Contudo, nos últimos anos, estudos têm comprovado a melhor qualidade e a maior variedade de rações comerciais com fonte única de proteína e de carboidrato que podem ser utilizadas para o diagnóstico e a manutenção em 
longo prazo de animais comprovadamente alérgicos (Kwochka, 2000).

Dietas comerciais de eliminação, mais recentes, têm sido formuladas com proteínas hidrolisadas na tentativa de diminuir o tamanho das partículas alimentares antigênicas e, assim, diminuir sua exposição ao sistema imunológico (Scott et al., 2001; Kennis, 2006; Loeffler et al., 2006; Puidgemont et al., 2006).

A resposta à corticoideterapia, 10 em 11 animais $(90 \%)$, confirma os resultados favoráveis obtidos por Rosser (1993) e Kwochka (2000) a essa classe de antipruriginosos esteroidais. Esses autores verificaram melhora entre $72 \%$ e $83 \%$ dos casos tratados. Esse fato contrapõe-se às antigas assertivas de que os cães com hipersensibilidade alimentar apresentariam má resposta a doses anti-inflamatórias de corticosteroides. Realmente não há uma justificativa plausível para tal fato. Acreditavam os autores que, por estabilizar as membranas lisossomais, os corticosteroides interfeririam na liberação de enzimas, diminuindo a digestão de partículas de alimentos e, consequentemente, aumentando $\mathrm{o}$ transporte de antígenos alimentares através da mucosa intestinal (Baker, 1990). Isto não encontra respaldo científico.

\section{REFERÊNCIAS BIBLIOGRÁFICAS}

BAKER, E. Small animal allergy: a practical guide. London: Lea \& Febiger, 1990. Food Allergy. p.94-112.

FADOK, V.A. Diagnosing and managing the food-allergic dog. Comp. Cont. Educ., v.16, p.1541- 5, 1994.

GROSS, T.L.; IHRKE, P.J.; WALDER, E.J. et al. Skin diseases of the dog and cat. clinical and histopathologic diagnosis. Oxford: Blackwell Science, 2005. Food Allergy. p.206-207.

JACKSON, H.A. Food allergy: A clinician's perspective. In: WORLD CONGRESS OF VETERINARY DERMATOLOGY, 5., Viena, 2004. Proceedings... Viena, 2004. p.336-337.

JEFFERS, J.G.; SHANLEY, K.J.; MEYER, E.K. Diagnostic testing of dogs for food hypersensitivity. J. Am. Vet. Med. Assoc., v.198, p.245-250, 1991.
KENNIS, R.A. Food allergies: Update of pathogenesis, diagnoses and management. Vet. Clin. Small Anim. Pract., v.36, p.175-184, 2006.

KWOCHKA, K.W. The clinical management of food-related dermatoses. In: NORTH AMERICAN VETERINARY CONFERENCE, Orlando, 2000. Proceedings... Orlando, 2000. p.213-215.

LOEFFLER, A.; SOARES-MAGALHÃES, R.; BOND, R. et al. Retrospective Analysis of case series using home-prepared and chicken hydrolyzate diets in the diagnosis of adverse food reactions in 181 pruritic dogs. Eur. Soc. Vet. Dermatol. J. Compil., v.17, p.273-279, 2006.

MacDONALD, J.M. Food allergy. In: Current veterinary dermatology, the science and art of therapy. Saint Louis: Mosby Year Book, 1993. p. 121-32.

MARTIN, A.; SIERRA, M.; GONZALEZ, J.L. et al. Identification of allergens responsible for canine cutaneous adverse food reactions to lamb, beef and cow's milk. Vet. Dermatol., v.15, p.349-356, 2004.

MULLER, G.H.; KIRK, R.W.; SCOTT, D.W. Small animal dermatology. Philadelphia: W.B. Saunders, 1989. Food hypersensitivity (Food Allergy). p.470-474.

PUIGDEMONT, A.; BRAZIS, P.; SERRA, M. et al. Immunologic responses against hydrolyzed soy protein in dogs with experimentally induced soy hypersensitivity. Am. J. Vet. Res., v.67, p.484-488, 2006.

RHODES, K.H. Food hypersensitivity/intolerance. In: ANNUAL WALTHAM SYMPOSIUM, 19., Ohio, 1995. Anais... Ohio, 1995. p.12-16.

ROSSER, E.J. Diagnosis of food allergy in dogs. J. Am. Vet. Med. Assoc., v.203, p.259-262, 1993.

ROUDEBUSH, P.; COWELL, C.S. Results of a hypoallergenic diet survey of veterinarians in north america with a nutritional evaluation of homemade diet prescriptions. Vet. Dermatol., v.3, p.23-28, 1992.

ROUDEBUSH, P. Adverse reactions to food: nutritionist perspective. In: WORLD CONGRESS OF VETERINARY DERMATOLOGY, 5., Viena, 2004. Proceedings... Viena, 2004. p.328-335.

SCOTT, D.W.; MILLER Jr., W.H.; GRIFFIN, C.E. Small animal dermatology. Philadelphia: W.B. Saunders, 2001. Canine food hypersensitivity. p.624-627.

SIEGEL, S. Estatística não paramétrica para as ciências do comportamento. São Paulo: McGraw-Hill, 1975.

WHITE, P.D. Food allergy dermatitis. In: NORTH AMERICAN VETERINARY CONFERENCE, Orlando. Proceedings... Orlando, 2000. p.230-231.

WHITE, S.D. Food hypersensitivity. In: BIRCHARD, S.J.; SHERDING, R.G. Saunders manual of small animal practice. Philadelphia: W.B. Saunders, 1994. p.310-312. 